Article

\title{
Progress in the Utilization of Coal Fly Ash by Conversion to Zeolites with Green Energy Applications
}

\author{
Silviya Boycheva ${ }^{1, *}$, Denitza Zgureva ${ }^{2}\left(\mathbb{D}\right.$, Katerina Lazarova $^{3}$, Tsvetanka Babeva $^{3, *(\mathbb{D})}$ \\ Cyril Popov ${ }^{4}$, Hristina Lazarova ${ }^{5}$ and Margarita Popova ${ }^{5}$ \\ 1 Department of Thermal and Nuclear Power Engineering, Technical University of Sofia, 8 Kl. Ohridsky Blvd, \\ 1000 Sofia, Bulgaria \\ 2 College of Energy and Electronics, Technical University of Sofia, 8 Kl. Ohridsky Blvd, 1000 Sofia, Bulgaria; \\ dzgureva@gmail.com \\ 3 Institute of Optical Materials and Technologies "Acad. J. Malinowski”, Bulgarian Academy of Sciences, \\ Acad. G. Bonchev Str., bl.109, 1113 Sofia, Bulgaria; klazarova@iomt.bas.bg \\ 4 Institute of Nanostructure Technologies and Analytics (INA), University of Kassel, Heinrich-Plett-Str. 40, \\ 34132 Kassel, Germany; popov@ina.uni-kassel.de \\ 5 Institute of Organic Chemistry with Centre of Phytochemistry, Bulgarian Academy of Sciences, bl.9, \\ 1113 Sofia, Bulgaria; lazarova@orgchm.bas.bg (H.L.); mpopova@orgchm.bas.bg (M.P.) \\ * Correspondence: sboycheva@tu-sofia.bg (S.B.); babeva@iomt.bas.bg (T.B.)
}

Received: 20 March 2020; Accepted: 22 April 2020; Published: 25 April 2020

\begin{abstract}
Fly ash (FA) from lignite coal combusted in different Thermal Power Plants (TPPs) was used for the synthesis of zeolites (FAZs) of the Na-X type by alkaline activation via three laboratory procedures. FAZs were characterized with respect to their morphology, phase composition and surface properties, which predetermine their suitability for applications as catalysts and adsorbents. FAZs were subsequently modified with metal oxides $(\mathrm{CuO})$ to improve their catalytic properties. The catalytic activity of non-modified and $\mathrm{CuO}$-modified FAZs in the total oxidation of volatile organic compounds was investigated. FAZs were studied for their potential to retain $\mathrm{CO}_{2}$, as their favorable surface characteristics and the presence of iron oxides make them suitable for carbon capture technologies. Thin films of FAZs were deposited by in situ crystallization, and investigated for their morphology and optical sensitivity when exposed to pollutants in the gas phase, e.g., acetone. This study contributes to the development of novel technological solutions for the smart and valuable utilization of FA in the context of the circular economy and green energy production.
\end{abstract}

Keywords: fly ash utilization; fly ash zeolites; catalytic oxidation of VOCs; $\mathrm{CO}_{2}$ adsorption; fly ash zeolite films

\section{Introduction}

Coal remains the main energy source on a global scale. The combustion of coal in Thermal Power Plants (TPPs) generates numerous atmospheric pollutants, including fine particulate matters. The discharge of ash particles (fly ash, FA) into the atmosphere is avoided by their separation from flue gases in dust collectors. However, the subsequent landfilling of FA poses risks to the environment due to changes in the chemistry of the ground water, acidification of soils, and accumulation of potentially toxic elements [1]. The current increased responsibility for environmental protection requires the development of a new generation of coal-fired TPPs via the implementation of near zero-emission and waste recovery technologies. In this context, FA from coal is considered a raw material rather than a waste, and in industrial settings it is utilized in applications such as concrete production, road 
base construction, and soil amendment [2,3]. However, these applications reduce the amounts of solid wastes, but do not exploit fully the potential uses of this abundant resource $[4,5]$. Therefore, smart and more practically valuable approaches for the utilization of FA have been under development in recent years. For example, fly ash particles have been investigated as fillers in polymers [6], in the processing of architectural ceramics [7], and as a source of other valuable materials [8,9]. The conversion of FA into zeolites has potentially the greatest environmental benefits due to the broad application of these materials in water-, air- and soil-cleaning technologies.

Coal fly ash zeolites (FAZs) are intensively investigated regarding their potential applications in waste water remediation, flue gas purification, and for catalytic degradation of air contaminants [10-12]. FAZs are typically characterized by smaller specific surface area when compared to their pure synthetic counterparts or natural minerals. Meanwhile, these materials possess a number of advantages that make them valuable for the practice. Coal fly ash zeolites are distinguished in their significant content of iron oxides $\left(\gamma-\mathrm{Fe}_{2} \mathrm{O}_{3}, \alpha-\mathrm{Fe}_{2} \mathrm{O}_{3}, \gamma-\mathrm{Fe}_{3} \mathrm{O}_{4}\right)$ and doping elements (e.g., $\left.\mathrm{Cu}, \mathrm{Co}, \mathrm{Mn}, \mathrm{V}, \mathrm{W}\right)$ transferred from raw FA. The presence of spinel iron oxides gives FAZs magnetic properties, whereas the uniform distributions of $\mathrm{Fe}^{2+} / \mathrm{Fe}^{3+}$ centers and metal nanoparticles are a prerequisite for their excellent catalytic activity [12]. In addition, the formation of Brønsted acidic sites on the porous aluminosilicate structural framework of FAZs stipulates their performance as efficient catalytic systems, integrating a carrier and active sites. This allows for the application of FAZs in the oxidative degradation of volatile organic compounds (VOCs). VOCs are harmful atmospheric pollutants generated in manufacturing and the use of paints, varnishes and solvents; they are emitted as direct or secondary products from transportation and combustion of petrol fuels, biomass, and wastes [13]. Noble metals (Pt and Pd) are among the most employed catalysts for the thermal degradation of VOCs, but since they are expensive and sensitive to poisoning, their low-cost alternatives are intensively studied [14]. Suitable substitutes of the expensive noble metal catalysts are the materials containing transition metals $(\mathrm{Co}, \mathrm{Cu}$, $\mathrm{Fe}, \mathrm{Cr}$, etc.), whose fine dispersion onto porous supports with high surface area creates difficulties to obtaining efficient catalytically active systems [15]. FAZs are porous matrices with distributed active centers, and can be considered as viable alternatives to catalytic systems for the oxidation of VOCs. The efficiency of FAZ catalysts can be further improved via post-synthesis modification with metal oxides.

FAZs are also distinguished by their mixed micro-mesoporous structure, facilitating mass transport phenomena through the material, which is beneficial for their adsorption and catalytic applications [16]. Due to their strong surface unsaturation, FAZs have adsorption potential comparable to their pure synthetic analogues and outperform them in a more energy-efficient desorption process [17]. The potential use of FAZs as adsorbents in carbon capture technologies offers a technological solution for closed-cycle environmental protection in coal-fired TPPs. For these purposes, FA can be converted into $\mathrm{CO}_{2}$ adsorbents, thus reducing, at the same time, the environmental impact of both solid waste and greenhouse gases generated by combustion processes. Recent studies on the $\mathrm{CO}_{2}$ adsorption capacities of FAZs have revealed promising results $[17,18]$. It has been established that among the zeolites, faujasite (FAU) and linde (LTA) types possess the greatest potential for $\mathrm{CO}_{2}$ capture due to the favorable combination of their thermal and mechanical stability, and their beneficial structural frameworks with appropriate pore sizes [19]. $\mathrm{CO}_{2}$ uptake onto zeolites can be improved further, not only by the optimization of operational conditions, but also by modifying their microporous structure to create hierarchical micro-mesoporosity. In addition, lowering $\mathrm{Si}$ to $\mathrm{Al}$ ratio in the zeolite composition will increase the surface heterogeneity and strengthen the electrostatic field inside the pores, enhancing the adsorption of $\mathrm{CO}_{2}$ [20]. The type of the compensating cations in the zeolite framework also impacts strongly on their $\mathrm{CO}_{2}$ adsorption potential [21]. A zeolite of FAU type (Na-X) has been selectively synthesized from high-silica FA by a double-stage fusion-hydrothermal activation, reaching up to $62 \%$ crystallinity [22]. Multistage fusion-hydrothermal synthesis preceded by FA calcinations and acidic treatment was performed by Volli and Purkait [23] to obtain single-phase zeolite Na-X. However, middling specific surface values of about $160 \mathrm{~m}^{2} / \mathrm{g}$ FAZ have been reported. 
The optimization of procedures for conversion of FA to zeolite Na-X, which is one of the zeolites with huge practical importance, regarding the yield of the main phase, as well as the economy and energy efficiency of the process, is of significant practical concern. It has been observed that FAZ of Na-X type can be also obtained by applying low- or zero-energy synthesis methods, such as a single stage of hydrothermal activation and long-term crystallization at ambient conditions [24,25]. However, the hydrothermal alkaline treatment of FA results in the low crystallinity of $\mathrm{Na}-\mathrm{X}$ and in the crystallization of accompanied phases in the zeolite products [24]. Alkaline aging of FA at ambient conditions leads to a significant yield of the zeolite $\mathrm{Na}-\mathrm{X}$ formation after long-term incubation of the reaction mixtures for several months. Thus, the need for external energy is eliminated and the equipment required is simplified [25]. Despite the technological drawbacks of the hydrothermal and long-term aging processes, the benefits of these processes should be considered as viable ways of processing FA into zeolite $\mathrm{Na}-\mathrm{X}$ because of the low cost and technological simplicity of the processes. Bearing in mind that the coal ash wastes are deposited for a long period, the duration of their processing is not a meaningful critical issue.

FAZs are also considered as optional materials in $\mathrm{CO}_{2}$ capture due to their low-cost processing [18]. Moreover, these materials are promising adsorbents due to their mixed porosity, and high surface heterogeneity. FAZs also contain iron oxides that contribute to additional $\mathrm{CO}_{2}$ uptake mechanisms [26].

The great application potential of zeolite materials has not been fully explored, despite the fact that synthetic zeolites are broadly studied as adsorbents, molecular sieves, ion-exchangers and catalysts for industrial and environmental protection applications due to their unique surface properties [27]. The processing of zeolite thin film and membranes will reveal novel opportunities for their advanced applications. Experimental studies on the deposition of pure zeolite thin films with controllable phase composition have been performed by spin casting or nozzle spray of colloidal suspensions [28,29], in situ crystallization [30], and dry gel conversion [31]. Zeolite membranes are distinguished by unique adsorption and separation properties combined with high selectivity due to their ordered micro-porosity in the structural framework [32]. Zeolite thin films are promising sensing media because of their adsorption properties and ability to host molecules of sensing substances [33]. The embedding of metal nanoparticles in mesoporous oxide thin films results in novel nanocomposite materials with advanced optical, catalytic, and sensing properties derived from the structural synergy of the matrix and the hosted active centers [34]. As the FA is, at the same time, a source of silica, alumina and iron oxides, it could be expected that this initial chemical composition is a prerequisite for the deposition of thin layers of self-assembled composites of zeolite-like matrixes with meso-porous structures, including distributed nanoparticles of iron oxides. At present, the scientific literature on deposition and studies of FAZ thin films is limited to initial investigations on coatings consisting of a sol-gel $\mathrm{Nb}_{2} \mathrm{O}_{5}$ matrix doped with fly ash zeolites [35].

The present paper summarizes our best attempts at the synthesis of zeolites of $\mathrm{Na}-\mathrm{X}$ type from class $\mathrm{F}$ lignite coal fly ash and outlines their possible application in environmental protection systems as adsorbents of carbon dioxide and catalysts for the total oxidation of VOCs. This study complements the existing knowledge, with the comparison of coal ash zeolites $\mathrm{Na}-\mathrm{X}$ obtained through various synthesis and homogenization techniques, which are reflected in their compositional and textural characteristics. The present study compares the influence of magnetic homogenization and ultrasonic activation of the reaction mixtures on the properties of coal ash zeolites in relation to their use as adsorbents and catalysts. This is the first demonstration of the in situ deposition of thin film of coal ash zeolites and their potential for advanced applications as sensitive media.

\section{Materials and Methods}

\subsection{Characterization of the Raw Material}

Fly ash generated by the combustion of lignite coal from the largest coal field located in the area of Radnevo, Bulgaria, "Maritsa East", was used as a raw material for the synthesis of zeolites. 
FA was sampled from the electrostatic precipitators of the three main local Thermal Power Plants

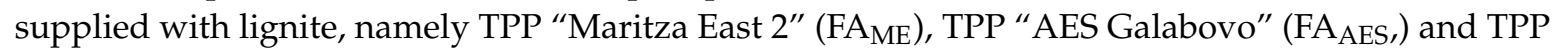
"Contour Global" (FA $\mathrm{FG}_{\mathrm{C}}$ ), which are three of the four main power plants in south-central Bulgaria's Maritsa East Energy Complex. The chemical composition of different FA samples was examined by common chemical analyses and atomic absorption spectroscopy, as described in [36]. The phase composition of FA samples was studied by X-ray diffraction analyses. Their density was measured pycnometrically, and their granulometry was determined by sieve analysis.

\subsection{Synthesis and Characterization of Coal Fly Ash Zeolites}

Powdery coal fly ash zeolites were synthesized by alkaline activation of lignite coal FA using three different laboratory procedures: hydrothermal activation $(\mathrm{H})$, double-stage fusion-hydrothermal activation (FH) and atmospheric crystallization (AA). In the hydrothermal activation, suspensions of $5 \mathrm{~g}$ FA in $100 \mathrm{~mL}$ of sodium hydroxide solutions with concentrations of $2.5 \mathrm{~mol} / \mathrm{L}$ in closed vessels were heated to $90^{\circ} \mathrm{C}$ and kept at this temperature for $2 \mathrm{~h}$. In the two-step fusion-hydrothermal synthesis, a preliminary alkaline melting step was carried out, in which solid phase mixtures of $5 \mathrm{~g}$ FA and $10 \mathrm{~g}$ sodium hydroxide were heated in nickel crucibles to $550^{\circ} \mathrm{C}$ for $1 \mathrm{~h}$. The obtained sintered mixtures were diluted in distilled water and subsequently subjected to hydrothermal activation. In both procedures, the reaction slurries were homogenized prior to the hydrothermal treatment by continuous magnetic stirring for $5 \mathrm{~h}$ (M mode) or by ultrasonic treatment (U mode) for $15 \mathrm{~min}$. The applied temperatures and durations of fusion and hydrothermal treatment were found to be optimal for the synthesis of zeolite Na-X in our previous studies [25]. It has been observed that zeolite $\mathrm{Na}-\mathrm{X}$ is crystallized from the reaction slurries of coal fly ash and alkaline solutions as a metastable phase, and its preparation requires moderate synthesis temperatures and short hydrothermal activation [36]. The optimal duration of magnetic homogenization and ultrasonic treatment of the reaction mixtures for the synthesis of zeolite $\mathrm{Na}-\mathrm{X}$ has been established experimentally [37]. The homogenization of the mixtures accelerated the release of the aluminosilicate components from the raw FA into the reaction solution in the form of soluble sodium aluminate and sodium silicate. In the third zeolitization approach, slurries of $10 \mathrm{~g}$ FA in $100 \mathrm{~mL}$ of $1.5 \mathrm{~mol} / \mathrm{L} \mathrm{NaOH}$ solutions in closed polypropylene containers were kept at room temperature over the course of 10 months. The laboratory procedures for the conversion of FA into zeolites are presented in Figure 1.

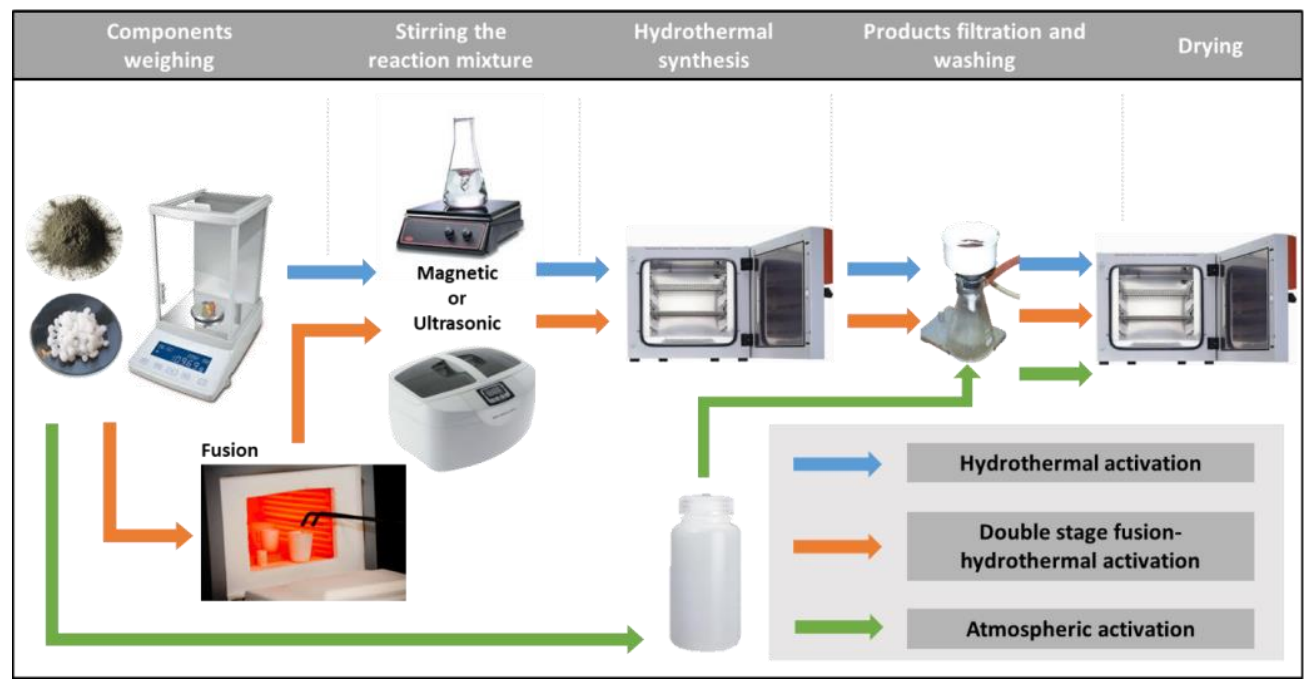

Figure 1. Synthesis of fly ash zeolites by hydrothermal activation, double-stage fusion-hydrothermal activation and atmospheric crystallization.

The obtained FAZ powders were separated by filtration of the reactant solutions, washed with distilled water and dried in an oven at $105^{\circ} \mathrm{C}$. The phase composition of the synthesized FAZs was 
studied by X-ray diffraction using a Brucker D2 Phaser diffractometer (Bucker Corporation, Germany,) with $\mathrm{CuK} \alpha$ radiation and an $\mathrm{Ni}$ filter. Their morphology was observed by scanning electron microscopy (SEM) using a Carl Zeiss SMT SEM EVO LS25 (Carl Zaiss AG, Germany) with an EDAX Trident system. The surface properties of FAZs were investigated via nitrogen adsorption/desorption isotherms measured at liquid nitrogen temperatures using a volumetric adsorption analyzer Tristar II 3020 (Micromeritics Instrument Corporation, USA. Brunauer-Emmett-Teller (BET)-specific surface area $\left(\mathrm{S}_{\mathrm{BET}}, \mathrm{m}^{2} / \mathrm{g}\right)$ was evaluated applying the multi-point Brunauer-Emmett-Teller (BET) model to the experimental adsorption data. The mesopore size was calculated by the Barrett-Joyner-Halenda (BJH) model using data from the desorption branch of the isotherms. The micropore volume was evaluated by applying a t-plot model.

\subsection{Deposition and Characterization of Fly Ash Zeolite Thin Films}

Fly ash zeolite thin films (FAZTFs) were deposited onto optical glass substrates by in situ hydrothermal crystallization. The substrates were seeded ultrasonically to create centers of nucleation and were then immersed into the zeolite growth solution. The hydrothermal deposition experiments were performed at $90^{\circ} \mathrm{C}$ with varying durations from 4 to $20 \mathrm{~h}$. The resultant coatings were inspected for surface morphology using a Jeol Superprobe 733 scanning electron microscope (JEOL, Tokyo, Japan) and for surface roughness using a Zygo Optical Profiler (Zygo Corporation, Middlefield, CT, USA) at a standard magnification of 50x. The optical transmittance and reflectance spectra were recorded with a high-precision Cary 5E spectrophotometer (Varian, Australia) at a normal light incidence in the wavelength region $\lambda=200-1200 \mathrm{~nm}$, with an accuracy of $0.1 \%$ and $0.3 \%$, respectively. The optical response towards VOCs was studied by reflectance measurements before and after exposure to vapors of acetone selected as probe molecules.

\subsection{Investigation of Potential Applications of FAZ}

\subsection{1. $\mathrm{CO}_{2}$ Adsorption}

The adsorption of $\mathrm{CO}_{2}$ onto FAZs was studied under equilibrium and dynamic conditions. The equilibrium adsorption potential was measured using Micromeritics equipment at $0{ }^{\circ} \mathrm{C}$ in the relative pressure range of $\mathrm{p} / \mathrm{p}_{0}=0.001-0.030$, where $\mathrm{p}_{0}$ is the saturation pressure of $\mathrm{CO}_{2}(3485.6769 \mathrm{kPa}$, $0{ }^{\circ} \mathrm{C}$ ). The $\mathrm{CO}_{2}$ adsorption on FAZs in dynamic conditions was examined in an adsorption reactor, passing a gas mixture of $10 \mathrm{vol} . \% \mathrm{CO}_{2} / \mathrm{N}_{2}$ at a flow rate of $30 \mathrm{~mL} / \mathrm{min}$ through the adsorbent-fixed bed. Prior to the adsorption tests, the samples were pre-treated in situ for $1 \mathrm{~h}$ in nitrogen flow at $400{ }^{\circ} \mathrm{C}$. The effluent gas was analyzed online by GC TCD with a $25 \mathrm{~m}$ PLOT Q and HP-5MS capillary columns.

\subsubsection{Catalytic Oxidation of VOCs}

Parent FAZs or modified FAZs with $\mathrm{CuO}(\mathrm{Cu}-\mathrm{FAZs})$ were studied in total oxidation of VOCs. $\mathrm{Cu}-\mathrm{FAZs}$ were obtained by an incipient wetness impregnation technique of the parent FAZs with $\mathrm{Cu}\left(\mathrm{NO}_{3}\right)_{2} \cdot 3 \mathrm{H}_{2} \mathrm{O}$. The copper salt was dissolved in distilled water in an amount corresponding to $5 \mathrm{wt} . \%$ of $\mathrm{Cu}$ loading, and mixed with FAZ materials. The catalysts were dried at ambient temperature and the salt precursor was decomposed at $400{ }^{\circ} \mathrm{C}$. The catalytic tests were performed using a fixed-bed flow reactor in the temperature range $250-550{ }^{\circ} \mathrm{C}$. All gas lines of the apparatus were heated to $110{ }^{\circ} \mathrm{C}$ in order to avoid VOC adsorption on the tube walls. Air used as a carrier gas with a flow rate of $30 \mathrm{~mL} / \mathrm{min}$ passed through a saturator filled with toluene (the model VOC) and fed into the reactor. A thermocouple was positioned in the catalyst bed for the accurate measurement of the catalyst temperature. The reaction steady state was established after $30 \mathrm{~min}$ at each temperature, until the only registered final products of VOC oxidation were $\mathrm{CO}_{2}$ and $\mathrm{H}_{2} \mathrm{O}$. An online analysis of the reaction products was performed using HP-GC (FID/TCD) with a $25 \mathrm{~m}$ PLOT Q and HP-5MS capillary columns [12].

Prior to the catalytic tests, the samples were pretreated for $1 \mathrm{~h}$ in nitrogen flow at $400{ }^{\circ} \mathrm{C}$. 


\section{Results}

\subsection{Characterization of Lignite Coal Fly Ash}

The chemical composition, density and granulometry of the FA generated from the lignite coal combusted in the three separate TPPs varied in the intervals listed in Table 1. The content of the main components in the FA compositions varies within $\pm 3 \mathrm{wt}$ \% of the average, depending on the incineration system. The density and granulometry of FA exhibit larger variations, most likely due to the specifics of the coal-grinding systems in the individual TPPs. FA from lignite coal from the "Maritza East" basin is attributed to class F according to the international crystallographic standard ASTM C618, because the total content of $\mathrm{SiO}_{2}+\mathrm{Al}_{2} \mathrm{O}_{3}+\mathrm{Fe}_{2} \mathrm{O}_{3}$ was above 70 wt. $\%$. CaO was under $20 \mathrm{wt} . \%$, regardless of the TPP in which the FA was generated.

Table 1. Variation in the chemical composition and some physicochemical properties of lignite coal fly ash (FA) sampled from different Thermal Power Plants (TPPs).

\begin{tabular}{cccccccc}
\hline Components & $\mathrm{SiO}_{2}$ & $\mathrm{Al}_{2} \mathrm{O}_{3}$ & $\mathrm{Fe}_{2} \mathrm{O}_{3}$ & $\mathrm{MgO}$ & $\mathrm{SO}_{3}$ & $\mathrm{CaO}$ & Others \\
\hline Content, wt. $\%$ & $50 \pm 3$ & $24 \pm 1$ & $12 \pm 3$ & $2 \pm 1$ & $2.25 \pm 0.25$ & $4.5 \pm 1.5$ & $<1$ \\
Si to Al molar ratio & & & & $3.3-3.8$ & & \\
Density, g/cm ${ }^{3}$ & & & & $1.9-3.1$ & \\
Granulometry, $\mu \mathrm{m}$ & & & & $45-250$ & & \\
\hline
\end{tabular}

A typical X-ray diffraction pattern of raw FA is plotted in Figure 2. The main crystalline phases of all FA samples are quartz $\left(\alpha-\mathrm{SiO}_{2}\right)$, mullite $\left(3 \mathrm{Al}_{2} \mathrm{O}_{3} \cdot 2 \mathrm{SiO}_{2}\right)$, hematite $\left(\alpha-\mathrm{Fe}_{2} \mathrm{O}_{3}\right)$ and magnetite $\left(\gamma-\mathrm{Fe}_{3} \mathrm{O}_{4}\right)$. A slight difference in Ca-containing phases is established in the phase composition of the samples collected from the different TPPs. Calcium oxide is sulfated to gypsum $\left(\mathrm{CaSO}_{4}\right)$ in $\mathrm{FA}_{\mathrm{ME}}$, while in $\mathrm{FA}_{\mathrm{AES}}$ and FACG it is included in the aluminosilicate-phase anorthite $\left(\mathrm{CaAl}_{2} \mathrm{Si}_{2} \mathrm{O}_{8}\right)$. However, the ratio of amorphous to crystalline constituents in the different FAs varies from 0.8 to 2.0 depending on the combustion systems.

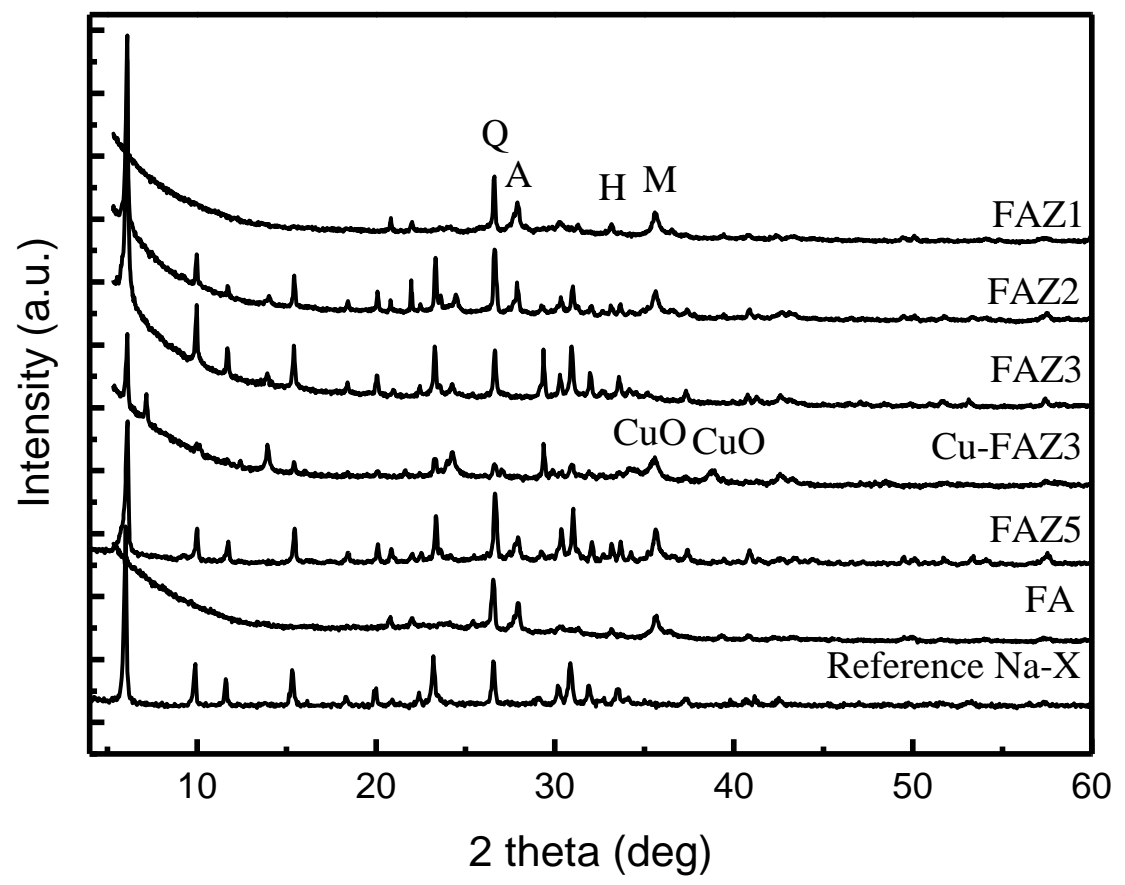

Figure 2. X-ray diffraction patterns of raw FA, reference Na-X, FAZs obtained by hydrothermal activation (FAZ1, FAZ2), double-stage fusion-hydrothermal synthesis (FAZ3) and atmospheric crystallization (FAZ5), and CuO-modified FAZ4 (Cu-FAZ4) (quartz (Q), anorthite (A), hematite (H), magnetite (M)). 


\subsection{Coal Fly Ash Zeolites}

The synthesis conditions and the sample notations are given in Table 2. X-ray diffractograms of FAZs obtained by different synthesis procedures are presented in Figure 2 in comparison to a diffraction pattern of a reference zeolite Na-X. The investigations performed on the lignite coal ash zeolitization reveal that the main zeolite phase, crystallized by three conversion approaches applied at the settled alkaline treatment conditions, is zeolite $\mathrm{Na}-\mathrm{X}$. The raw FA is highly silicically obeyed by the lignite coal chemistry, and it is a suitable starting material for the synthesis of zeolites of faujasite type, regardless of the source of its generation. The variation in the ash composition in the ranges indicated in Table 1 does not affect the type of zeolite phase obtained.

Table 2. Surface parameters and zeolitization extent of fly ash zelolites (FAZs), CuO-modified FAZs and a referent zeolite $\mathrm{Na}-\mathrm{X}$.

\begin{tabular}{|c|c|c|c|c|c|c|c|c|c|}
\hline Sample & $\begin{array}{c}\text { Synthesis } \\
\text { Mode * }\end{array}$ & Homoge-Nization ** & $\mathrm{S}_{\mathrm{BET}}, \mathrm{m}^{2} / \mathrm{g}$ & $\mathrm{S}_{\text {extern }} \mathrm{m}^{2} / \mathrm{g}$ & $\mathrm{V}_{\text {total }}, \mathrm{m}^{3} / \mathrm{g}$ & $\mathrm{V}_{\text {micro, }}, \mathrm{m}^{3} / \mathrm{g}$ & $\underset{\AA}{\mathrm{d}_{\text {micror }}}$ & $\begin{array}{c}\mathrm{d}_{\text {meso }} \\
\AA\end{array}$ & $\begin{array}{l}\text { Zeolitization } \\
\text { Extent, wt.\% }\end{array}$ \\
\hline FAZ1 & $\mathrm{H}$ & M & 73 & 67 & 0.11 & 0.02 & 11.03 & 50.17 & 13.35 \\
\hline FAZ2 & $\mathrm{H}$ & $\mathrm{U}$ & 280 & 87 & 0.21 & 0.08 & 13.81 & 49.98 & 51.40 \\
\hline FAZ4 & FH & $\mathrm{M}$ & 396 & 125 & 0.26 & 0.11 & 13.75 & 44.89 & 72.65 \\
\hline FAZ5 & AA & - & 283 & 98 & 0.20 & 0.07 & 13.65 & 43.33 & 49.60 \\
\hline $\mathrm{Cu}-\mathrm{FAZ3}$ & FH & $\mathrm{U}$ & 67 & 47 & 0.08 & 0.009 & 12.54 & 51.02 & - \\
\hline $\mathrm{Cu}-\mathrm{FAZ4}$ & FH & M & 224 & 76 & 0.16 & 0.06 & 13.76 & 46.07 & - \\
\hline
\end{tabular}

${ }^{*}$ Hydrothermal activation (H); atmospheric crystallization (AA); double-stage fusion-hydrothermal synthesis (FH);

** magnetic stirring $(\mathrm{M})$; ultrasonic treatment $(\mathrm{U})$.

Generally, the synthesis of zeolite $\mathrm{Na}-\mathrm{X}$ requires mild hydrothermal treatment temperatures $\left(90{ }^{\circ} \mathrm{C}\right)$, a short synthesis duration $(2-4 \mathrm{~h})$ and soft alkaline activator molarities $(2.5 \mathrm{~mol} / \mathrm{L})$, as it appears as a metastable zeolitic phase. Hydrothermal activation results in the low crystallinity of the zeolitization product when synthesizing defined zeolite phases. In general, an increase in zeolite yield is achieved if the product is a mixture of zeolite phases [37]. The alkaline resistant aluminosilicate phases in the raw FA, such as quartz, mullite and anorthite, are also observed in FAZs obtained by hydrothermal synthesis (samples FAZ1 and FAZ2), indicating that they are not utilized in this processing procedure (Figure 2).

The mild temperatures required for the crystallization of zeolite Na-X point out the possibility that this material can be obtained by converting the raw FA under room temperature, at the expense of longer processing times. The results reveal that the synthesis of Na-X FAZs via atmospheric aging requires the crystallization of FA in $1.5 \mathrm{~mol} / \mathrm{L} \mathrm{NaOH}$ over ten months. Despite the technological difficulties posed by the long conversion process to obtain a satisfactory degree of crystallization in the product, this technological variant for the extraction of FAU should not be neglected because of its benefits-zero-energy demands, low alkaline agent consumption and simple equipment. The conversion of FA to zeolites by atmospheric crystallization is feasible even at landfill sites. In the FAZs obtained by atmospheric crystallization, the alkaline-resistant phases in the raw material also remain unconverted, as their characteristic reflections are observed in the experimental X-ray diffractograms (Figure 2, sample FAZ 5). In the case of double-stage fusion-hydrothermal synthesis, the stable aluminosilicates in the FA are assimilated in the zeolitization process due to the high temperature treatment of the reaction mixture at $550{ }^{\circ} \mathrm{C}$ for $1 \mathrm{~h}$ prior to the hydrothermal activation. This was confirmed by the absence of their characteristic reflections in the X-ray diffractograms (Figure 2, sample FAZ 3). X-ray diffraction analyses reveal intensive lines of zeolite $\mathrm{Na}-\mathrm{X}$, indicating the strong crystallization of this zeolite phase in the samples obtained by double-stage syntheses.

The most important factors for the process of zeolitization of FA are the content, ratio and phase state of the Si- and Al-components in the composition of the raw material. Regarding its aluminosilicate components, the FA from the three TPPs is suitable for the synthesis of high-silica zeolites of the fuajasite type that require optimal molar ratios of $\mathrm{SiO}_{2} / \mathrm{Al}_{2} \mathrm{O}_{3}$ above three [10]. The higher amorphous part in FA facilitates the zeolitization process because of the better solubility of the amorphous aluminosilicates 
in the alkaline media. In contrast to this, the higher content of alkaline-resistant phases such as quartz $\left(\alpha-\mathrm{SiO}_{2}\right)$ and mullite $\left(\mathrm{Al}_{6} \mathrm{Si}_{2} \mathrm{O}_{13}\right)$ hinders the zeolitization. The dissolution of the crystalline aluminosilicates in the alkaline media is accelerated by the preliminary fusion stage.

The findings show that iron oxides do not influence the zeolitization, but are incorporated into the resulting zeolite structure, appearing as seeds around which zeolite crystals grow, or as nanoparticles incorporated into the cages and channels of the zeolite structures. Ferrous and ferric ions released by the alkaline dissolution of the amorphous constituents of the FA can also take part as compensating cations in the zeolite frameworks. The synthesis of FAZs via hydrothermal activation at moderate temperatures ensures the transfer of spinel and non-spinel ferrous oxides into the reaction products [38]. High-temperature alkaline melting leads to the oxidation of spinel iron oxides, resulting in hematite formation [39].

The homogenization of the reaction mixtures prior to the hydrothermal treatment was carried out using two different methods: magnetic stirring or ultrasonication. Figure 3 presents the SEM micrographs of the raw FA and FAZs of Na-X type obtained by atmospheric crystallization and double-stage fusion-hydrothermal syntheses with continuous magnetic stirring or short ultrasonic treatment.

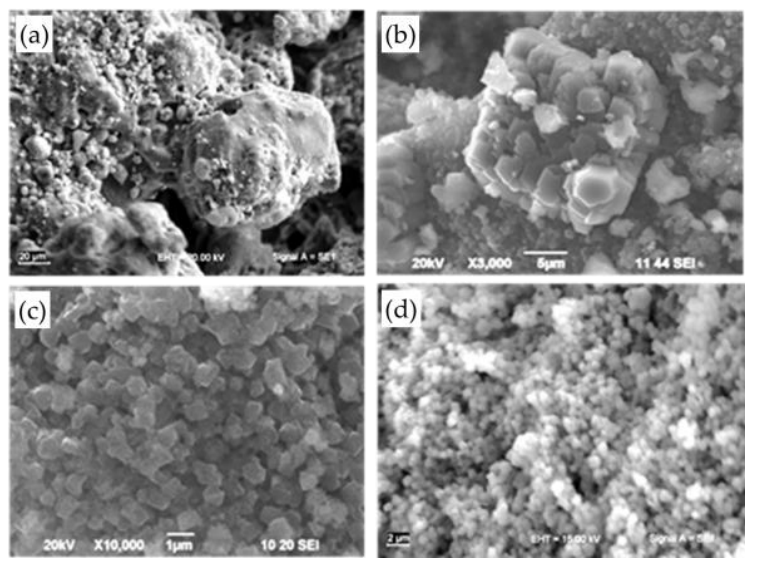

Figure 3. SEM images of raw FA (a) and FAZs synthesized by atmospheric crystallization (b), fusion-hydrothermal synthesis with magnetic stirring (c), and ultrasonic homogenization (d).

FA is composed of species of micron sizes with different morphologies (Figure 3a). The crystallites of the zeolite Na-X exhibit various morphologies depending on the synthesis and the homogenization procedures applied. Samples obtained by atmospheric crystallization are composed of agglomerates (Figure 3b), while the FAZs crystallized from the preliminary magnetically or ultrasonically homogenized slurries are composed of individual crystals (Figure 3c,d). Ultrasonic treatment of the reaction mixtures results in nanocrystalline synthesis products (Figure 3d), while the magnetic stirring leads to the formation of micron-sized crystallites (Figure 3c).

Table 2 presents the results for the main surface parameters of selected FAZs of Na-X zeolite type obtained by different synthesis modes. The surface characteristics of a reference zeolite $\mathrm{Na}-\mathrm{X}$ synthesized from pure starting materials in a stoichiometric ratio are presented for comparison. Typical experimentally measured $\mathrm{N}_{2}$ adsorption/desorption isotherms of FAZs are plotted in Figure 4 . The figure reveals the different adsorption stages: (i) fast filling in micropores at low pressure ratios $\mathrm{p} / \mathrm{p}_{0}$, (ii) the region of monolayer formation (isotherm's knee), and (iii) continued adsorption in mesopores at $\mathrm{p} / \mathrm{p}_{0}$ above 0.003 . Well-expressed hysteresis loops are exhibited between the adsorption and desorption branches of the isotherms for all investigated FAZs. The values of BET-specific surface areas $\left(\mathrm{S}_{\mathrm{BET}}, \mathrm{m}^{2} / \mathrm{g}\right)$, external surface areas $\left(\mathrm{S}_{\text {extern }}, \mathrm{m}^{2} / \mathrm{g}\right)$, total $\left(\mathrm{V}_{\text {total }}, \mathrm{m}^{3} / \mathrm{g}\right)$ and micro pore volumes $\left(\mathrm{V}_{\text {micro }}, \mathrm{m}^{3} / \mathrm{g}\right)$, diameters of micro- $\left(\mathrm{d}_{\text {micro }}, \AA\right)$ and mesopores $\left(\mathrm{d}_{\text {meso }}, \AA\right)$ were calculated by model studies of the isotherm data (Table 2). The $S_{\text {BET }}$ of FAZs varies in the range of $73-486 \mathrm{~m}^{2} / \mathrm{g}$. The lowest specific surface value was measured for the FAZ synthesized by hydrothermal treatment, 
while the highest $\mathrm{S}_{\mathrm{BET}}$ value was achieved for FAZ3 obtained by ultrasonically assisted double-stage fusion-hydrothermal synthesis. The ultrasonic homogenization contributes to the expansion of the specific surface area for both two-stage and hydrothermal syntheses.

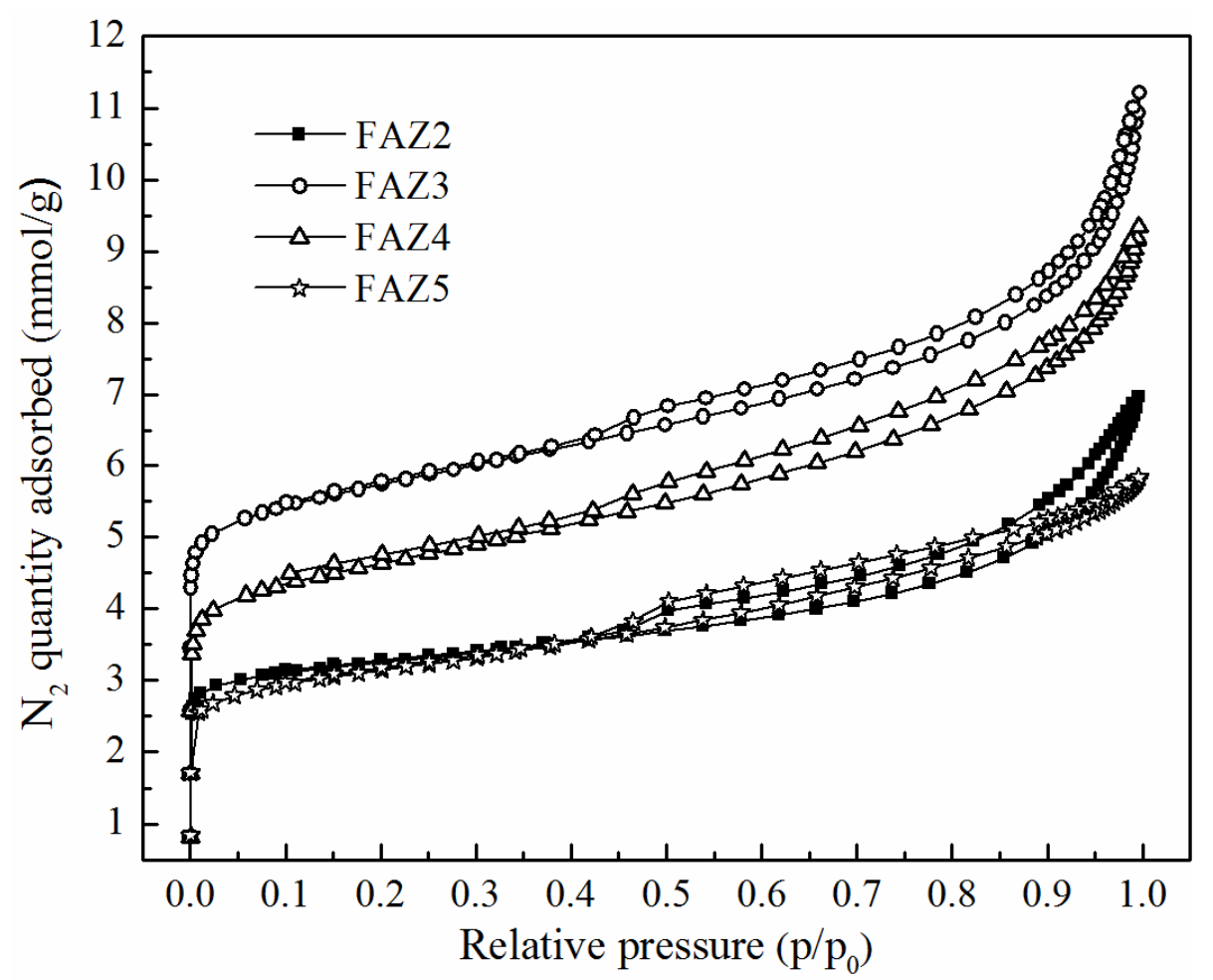

Figure 4. Experimental $\mathrm{N}_{2}$ adsorption/desorption isotherms of FAZs.

The $\mathrm{S}_{\mathrm{BET}}$ values of coal ash zeolites remain lower in comparison with those of the pure synthetic zeolite Na-X. FAZs are characterized by a mixed micro-mesoporous structure, as revealed by the experimental $\mathrm{N}_{2}$ adsoption/desorption and model porosity studies. $\mathrm{N}_{2}$ isotherms of FAZs can be assigned to type IV, according to the International Union of Pure and Applied Chemistry (IUPAC) classification (1985), with broad hysteresis loops of the H3 type typical of micro-mesoporous textural materials. The values of the volume described by micropores $V_{\text {micro }}\left(\mathrm{m}^{3} / \mathrm{g}\right)$ are higher for the ultrasonicated FAZs than in the cases when magnetic stirring was applied, which indicates that ultrasonic treatment results in a higher share of microporosity (Table 2).

The zeolitization extent $Z$ for FAZs of Na- $X$ type is calculated on the basis of the $S_{\text {BET }}$ values reported in Table 2 and by applying the following equation:

$$
\mathrm{Z}=\frac{\mathrm{S}_{\mathrm{BET}, \exp }}{\mathrm{S}_{\mathrm{BET}, \mathrm{ref}}} \frac{1}{\left(\mathrm{SiO}_{2}+\mathrm{Al}_{2} \mathrm{O}_{3}\right)} 100, \mathrm{wt} . \%
$$

where $Z$ is the yield of the zeolite Na-X phase from the aluminosilicate part of the raw $F A$, wt. $\%, S_{B E T, e x p}$ and $\mathrm{S}_{\mathrm{BET} \text {,ref }}$ are the BET specific surface areas for FAZ and the referent zeolite $\mathrm{Na}-\mathrm{X}$, correspondingly and $\mathrm{SiO}_{2}$ and $\mathrm{Al}_{2} \mathrm{O}_{3}$ are the contents of the corresponding components in the FA composition, wt.\%/100.

The evaluation of zeolitization extent based on specific surface values is one of the reliable methods applied, as discussed by Majchrzak-Kuceba [40].

A higher zeolitization extent is achieved at higher amorphous to crystalline ratios in the raw FA due to the faster alkaline dissolution of the amorphous aluminosilicates when compared to the crystalline phases. A maximal Na-X zeolite yield of $89 \mathrm{wt} . \%$ from the aluminosilicate part of the raw material was achieved by applying a double-stage fusion-hydrothermal synthesis in combination with ultrasonic treatment. 


\subsection{Fly Ash Zeolite Thin Films}

Typical SEM micrographs and optical profilograms of fly ash zeolite thin films (FAZTFs) are presented in Figure 5. The morphological studies reveal the formation of a continuous layer after at least $8 \mathrm{~h}$ of deposition. A smooth and uniform surface was obtained for the FAZTF2 after $12 \mathrm{~h}$ of crystallization. The longer deposition period results in a higher roughness and a more granular microstructure. The optical transmittance and reflectance spectra of FAZTFs obtained for different deposition times are plotted in Figure $6 a, b$, respectively. The films are characterized by high transmittance in the visible and near IR (VIS-NIR) spectral ranges; the transmission coefficient values decrease after a longer crystallization duration.
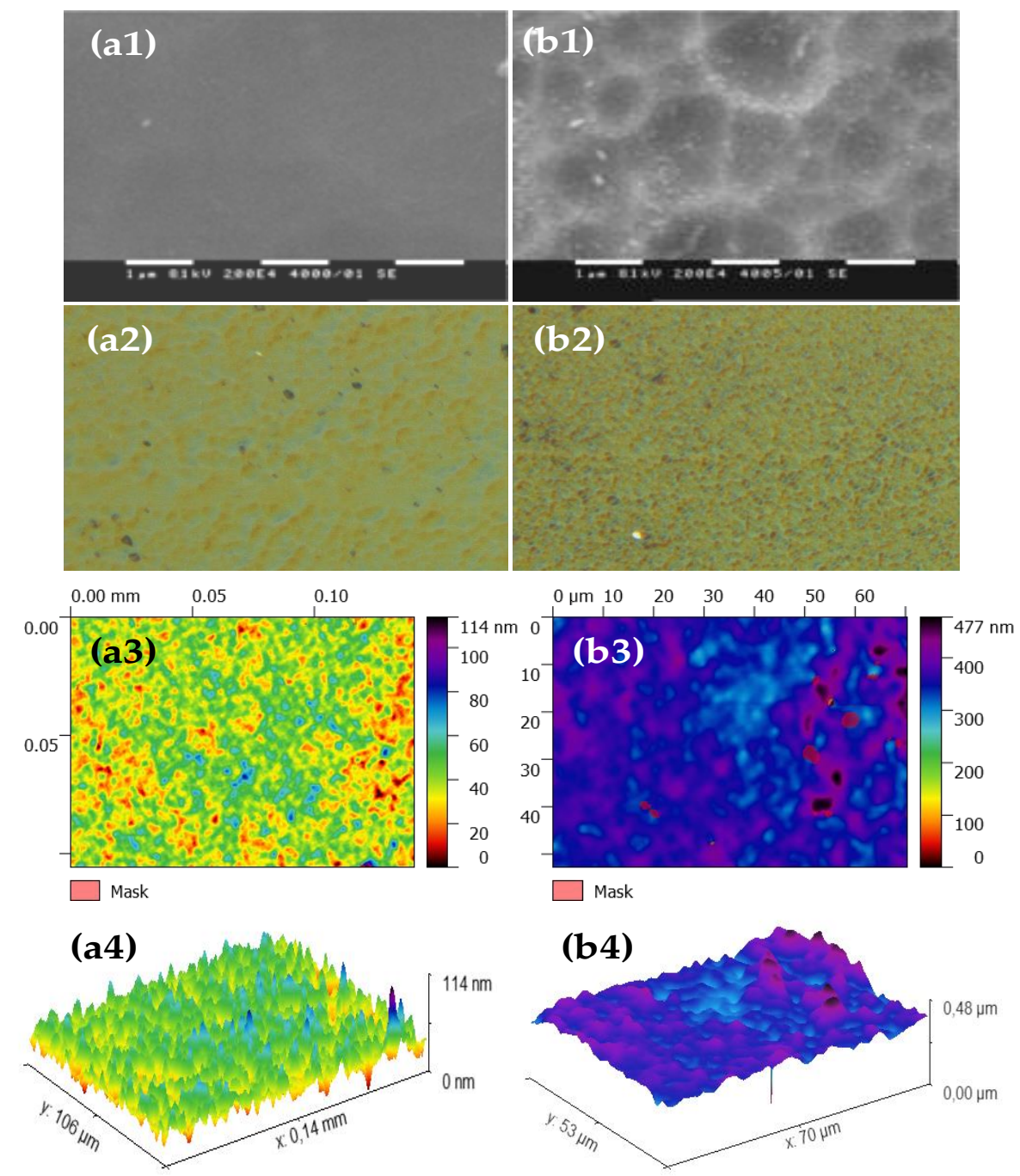

Figure 5. SEM micrographs (a1), optical microscope images (a2) and profilograms (top view (a3) and profile view (a4)) of fly ash zeolite thin films (FAZTFs) obtained at different crystallization durations: (a) hydrothermal activation for 12 hours; (b) hydrothermal activation for 20 hours.

Figure $6 \mathrm{c}$ presents the relative change in the reflectance after exposure of FAZTFs to acetone vapors. When porous films are exposed to acetone vapors, condensation takes place in the pores. As a result, the effective refractive index of the films increases because air (refractive index of 1) is replaced by a material with a higher refractive index (i.e., liquid acetone). Since the film reflectance is a function of the film optical constants, a change in the reflectance spectra is observed as well. Figure $6 \mathrm{c}$ shows that the reflectance response is the highest for the film FAZTF2 obtained after 12 hours of crystallization and that FAZTF2 possesses the smoothest surface. 

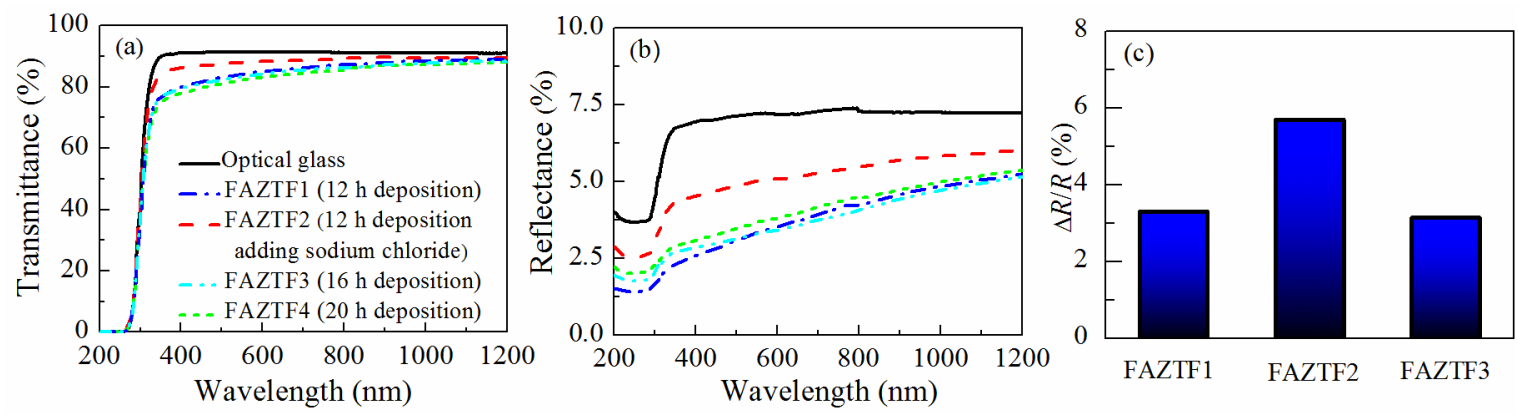

Figure 6. Optical transmittance (a) and reflectance (b) spectra of FAZTFs deposited at various crystallization times, and reflectance response (dR/R, \%) of FAZTFs exposed to acetone vapors (c).

\subsection{Adsorption Potential of FAZs for $\mathrm{CO}_{2}$ Capture}

Equilibrium adsorption isotherms of $\mathrm{CO}_{2}$ measured onto FAZs at $0{ }^{\circ} \mathrm{C}$ and pressure up to $105 \mathrm{kPa}$ are plotted in Figure 7a. Sonicated FAZs have lower adsorption capacity for $\mathrm{CO}_{2}$ relative to unit surface when compared to FAZs synthesized by the magnetic stirring of the reaction mixtures. Thus, despite its lower surface value, FAZ4 possesses a similar and even higher ability to capture $\mathrm{CO}_{2}$ compared to FAZ3; FAZ5 exhibits significantly higher adsorption capacity than FAZ2, despite their close $S_{\text {BET }}$ values. This trend can be explained by the differences in the external surface values $\left(S_{\text {extern }}, \mathrm{m}^{2} / \mathrm{g}\right)$ of the zeolite particles synthesized in different homogenization modes (Table 2). Ultrasonic treatment results in a higher share of $S_{\text {extern }}$ in the total $S_{B E T}$ value due to the smaller particle size of FAZs obtained by ultrasound-assisted syntheses. This leads to a lower adsorption into the pores of the zeolite framework. The iron oxides incorporated into the FAZ structural frameworks influence the $\mathrm{CO}_{2}$ adsorption capacity of the synthesized materials. Previous studies have shown that the iron oxide doping of zeolites increases $\mathrm{CO}_{2}$ adsorption due to the presence of a higher amount of coordinately unsaturated iron, creating various adsorption sites. These sites provoke a stronger interaction with $\mathrm{CO}_{2}$ molecules due to higher unsaturation on the solid surface and a stronger interaction between the adsorbent and the gas molecules [41]. In our previous studies, it was found that the sonicated FAZs obtained by a double-stage synthesis contain mostly ionic iron, which participates as a compensating cation in the zeolite framework compared to the zeolite samples obtained by magnetic stirring, in which iron oxides are predominately formed [12].
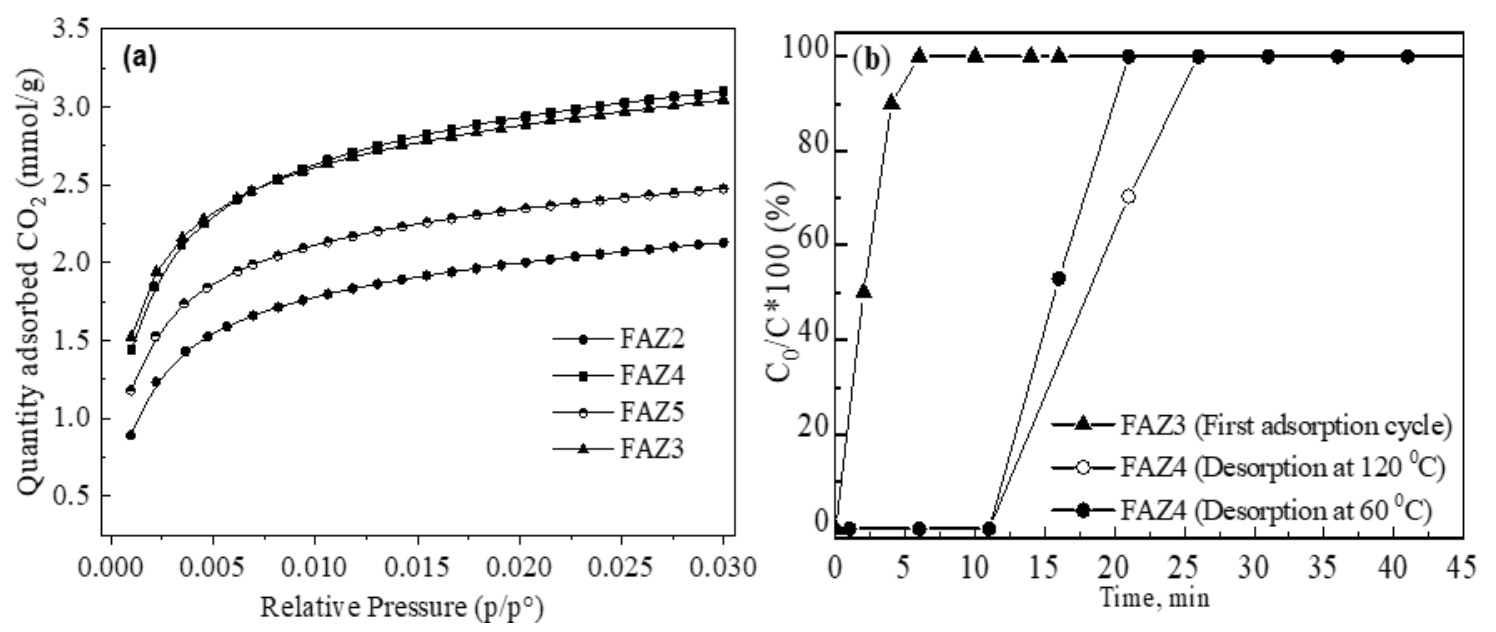

Figure 7. $\mathrm{CO}_{2}$ adsorption studies: equilibrium isotherms (a) and dynamic breakthrough curves (b).

The breakthrough curves of dynamic $\mathrm{CO}_{2}$ adsorption onto FAZ3 and FAZ4 at different temperatures of $\mathrm{CO}_{2}$ desorption are plotted in Figure $7 \mathrm{~b}$. The findings show that the $\mathrm{CO}_{2}$ adsorption process is faster for sonicated FAZs. This could also be explained by their higher external surface area, which ensures a shorter time for mass transfer. 
Synthetic faujasite and linde are considered the most promising zeolite adsorbents for carbon capture technologies due to the combination of their low-cost processing, large surface areas, acceptable adsorption potential of $\mathrm{CO}_{2}$ at ambient temperatures and atmospheric pressures, and high $\mathrm{CO}_{2} / \mathrm{N}_{2}$ separation capacity [42]. The disadvantages that limit their broad application for carbon capture include the high energy demands for their thermal recovery and the preferential adsorption of moisture. However, $\mathrm{CO}_{2}$ adsoption/desoption studies on FAZs demonstrate a favorable $\mathrm{CO}_{2}$ desorption process due to the textural peculiarities of these materials. Unlike the pure synthetic zeolites that are microporous, FAZs are distinguished with a mixed micro-mesoporous framework that facilitates mass transport phenomena through the material and favors the desorption process. Figure $7 \mathrm{~b}$ demonstrates the thermal recovery of the sample FAZ4. Breakthrough curves of dynamic $\mathrm{CO}_{2}$ adsortion onto the zeolite sample recovered at $120^{\circ} \mathrm{C}$ and $60^{\circ} \mathrm{C}$ are plotted. It is observed that FAZ4 retains its high adsorption capacity even at the lower regeneration temperature. For comparison, a lower recovery rate of microporous zeolites by thermal $\mathrm{CO}_{2}$ desorption was achieved at $300{ }^{\circ} \mathrm{C}$, as reported by Lee and Park [42]. This profitable thermal recovery of coal fly ash zeolites compared to their pure synthetic microporous analogues is obeyed by their mixed micro-mesoporous structure. FAZs possess a $\mathrm{CO}_{2}$ capture ability comparable to that of pure synthetic zeolites, in addition to a lower cost and favorable regeneration [17].

\subsection{Catalytic Activity of FAZs for Total Oxidation of VOCs}

The catalytic performance of FAZ3 and FAZ4 samples in the total oxidation of toluene is presented in Figure 8. These samples were selected because of their high surface area and the presence of finely distributed iron oxide particles, which can contribute active sites in the catalytic process. The sonicated sample FAZ3 exhibits stronger catalytic activity in the studied temperature range when compared to the sample obtained under magnetic stirring (Figure 8).

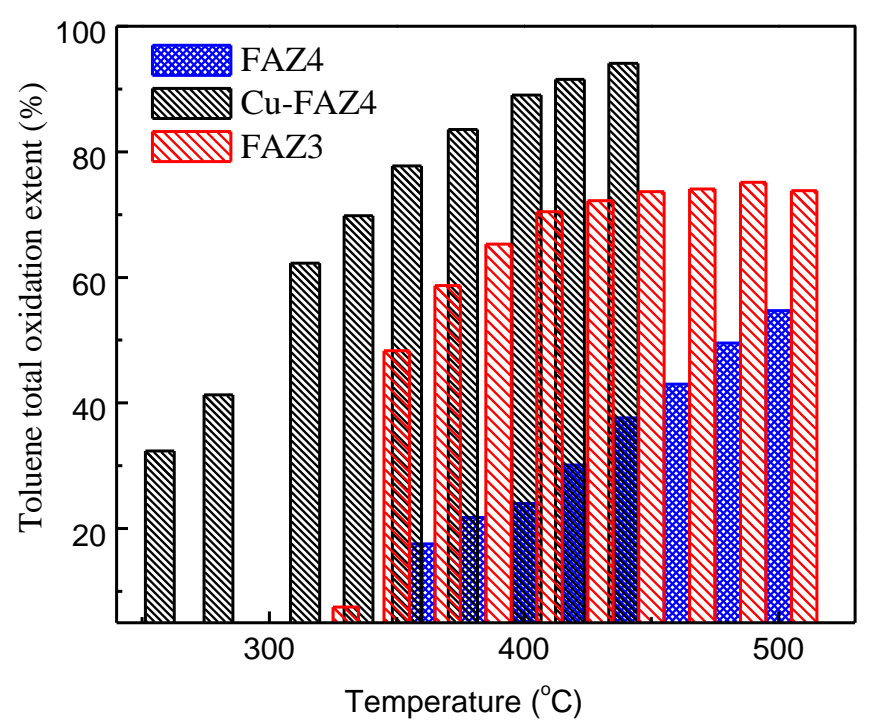

Figure 8. Toluene conversion extent at different temperatures of sonicated FAZ3, parent FAZ4 and CuO-modified FAZ4 obtained with magnetic stirring.

Modification with $\mathrm{CuO}$ significantly improves the catalytic ability of FAZ4 synthesized in M-mode, despite the reduction in the surface parameters due to the loading with metal oxide nanoparticles (see Table 2 and Figure 8). A toluene conversion rate of $50 \%$ was achieved at $300{ }^{\circ} \mathrm{C}$ for CuO-modified FAZ and at $480^{\circ} \mathrm{C}$ for the parent FAZ. Reflections typical for $\mathrm{CuO}$ crystallites are observed in the experimental X-ray diffractograms for $\mathrm{Cu}$-modified FAZ (Figure 2, Cu-FAZ4). The metal particles fill the micropores of the zeolite structure, reducing the internal volume determined by the micropores $\left(\mathrm{V}_{\text {micro }}\right)$ of the FAZs (Table 2). The reduction in the specific surface area of the modified samples is 
more pronounced for sonicated FAZs, as they yield more micropores (Table 2). The modification with metal oxide particles leads to a decrease in the surface area and pore volume of the $\mathrm{Cu}-\mathrm{FAZ}$ materials due to the pores filling with metal oxide species, but the distorting effects on the zeolitre structure due to the modification process cannot be excluded, as it was indicated by X-ray diffraction (Figure 2).

We demonstrate that the catalytic activity of FAZs in the total oxidation of toluene depends on the specific surface of the zeolite and the dispersion of iron oxide particles. The results of the catalytic activity of FAZs reveal an interaction between the metal oxide particles and the carrier that increases the number of active reaction sites on the surface of the catalysts. Due to the ultrasonic treatment, the sonicated FAZs are characterized by their nano-sized crystalline morphology, higher concentration and finer distribution of iron oxides, which serve as active centers for the easier release of oxygen atoms for the oxidation of VOCs. In contrast to the microporous zeolites, the mixed micro-mesoporous structure of coal ash zeolites improves their catalytic activity due to the accelerated transport of reagents across the material. The obtaining of hierarchical FAZs by modification with $\mathrm{CuO}$ particles significantly improves their catalytic performance due to the formation of additional active centers that facilitate the formation of oxygen defects (oxygen vacancies) on the catalyst surface, which are needed for the reaction process. The combination of the high catalytic activity of the modified FAZs in the total oxidation of VOCs (to $\mathrm{CO}_{2}$ and water) with the high adsorption potential for carbon emission capture of the initial FAZs reveals an opportunity for the development of a zero-emission VOC combustion technology based on solid waste utilization, which would provide significant environmental benefits.

\section{Conclusions}

Coal fly ash zeolites of Na-X type were obtained from coal ash with variable aluminosilicate content (within \pm 3 wt.\%) using three zeolitization techniques: atmospheric crystallization, hydrothermal activation, and double-stage fusion-hydrothermal activation. Depending on the homogenization of the reaction mixtures, magnetic stirring or ultrasonic treatment, coal ash zeolites of micro- and nanocrystalline morphology were obtained. A zeolitization extent of $89 \mathrm{wt} \%$ of the starting aluminosilicate composition can be achieved, with specific surface values of the resulting zeolite Na-X above $480 \mathrm{~m}^{2} / \mathrm{g}$, as demonstrated for the case of double-stage fusion-hydrothermal synthesis with ultrasonic treatment. The surface studies of the FAZs reveal a mixed micro-mesoporous texture that facilitates mass transport phenomena through the materials. Coal fly ash zeolites with a specific surface area of about $400 \mathrm{~m}^{2} / \mathrm{g}$ exhibit high $\mathrm{CO}_{2}$ adsorption capacity above $3.0 \mathrm{mmol} / \mathrm{g}$ FAZ under atmospheric pressure. The adsorption of $\mathrm{CO}_{2}$ under dynamic conditions proceeds faster with the zeolites synthesized by ultrasonic treatment, but when the magnetic stirring was used, a higher adsorption capacity per surface area of the zeolite was established. Due to the structural peculiarities, FAZs surpass their pure synthetic microporous analogues with lower energy demands for thermal recovery. A high regeneration rate was found at $60{ }^{\circ} \mathrm{C}$. Sonicated coal ash zeolites exhibit a stronger catalytic activity for the total oxidation of toluene above $75 \%$ at $490{ }^{\circ} \mathrm{C}$ compared to magnetically treated ones. The finer distribution of $\mathrm{Fe}^{2+} / \mathrm{Fe}^{3+}$-active centers in FAZ frameworks achieved by sonication leads to higher catalytic activity in the total oxidation of VOCs. A post-synthesis modification with the copper oxide of FAZs obtained under magnetic stirring significantly improves their catalytic activity due to the formation of additional catalytic sites. Copper-modified FAZs exhibit the total oxidation of toluene above $90 \%$ at $400{ }^{\circ} \mathrm{C}$. Coal ash zeolite thin films with uniform morphologies were deposited in situ onto optical glass substrates via the hydrothermal activation of alkaline coal ash slurries. An optical characterization of the obtained coal ash zeolite layers revealed promising results for further investigations of these materials as optical sensitive media. A significant change in the reflection coefficient was detected by the exposure of thin layers in acetone vapors.

Zeolites obtained from coal ash residues are promising candidates for applications in environmental protection systems for $\mathrm{CO}_{2}$ capture, catalytic degradation of volatile organic pollutants and the optical detection of air pollutants due to the unique combination of their particular morphology, composition, surface characteristics and low-cost processing. Studies will continue in the following directions: 
an investigation into the catalytic behavior of coal ash zeolites in mixtures of VOCs; an evaluation of the selectivity of $\mathrm{CO}_{2}$ adsorption in the presence of associated gases; model studies of the adsorption process; and the development of host-guest modifications of thin layers to increase their optical sensitivity. The use of the abundant coal ash resources in gas-cleaning technologies is a big step toward the realization of zero-emission power plants.

Author Contributions: Conceptualization, S.B., M.P. and T.B.; methodology, S.B., T.B. and M.P.; software, D.Z., K.L. and H.L; validation, D.Z., K.L. and H.L.; formal analysis, S.B., T.B., M.P. and C.P.; investigation, D.Z., K.L. and H.L.; resources, S.B., T.B., M.P. and C.P.; data curation, D.Z., K.L. and H.L.; writing-original draft preparation, S.B.; writing-review and editing, S.B., T.B., M.P. and C.P.; visualization, S.B., D.Z. and K.L.; supervision, S.B., M.P. and T.B.; project administration, S.B., M.P. and T.B.; funding acquisition, S.B. All authors have read and agreed to the published version of the manuscript.

Funding: This research received no external funding.

Acknowledgments: The financial support of Bulgarian National Science Fund under the project DN 17/18 (12.12.2017) is highly appreciated. Research equipment from the distributed research infrastructure INFRAMAT (part of the Bulgarian National roadmap for research infrastructures) supported by the Bulgarian Ministry of Education and Science under contract D01-284/17.12.2019 was partially used in this investigation.

Conflicts of Interest: The authors declare no conflict of interest.

\section{References}

1. Ferraiolo, G.; Zilli, M.; Converti, A. Fly ash disposal and utilization. J. Chem. Technol. Biotechnol. 2007, 47, 281-305. [CrossRef]

2. Basu, M.; Pande, M.; Bhadoria, P.B.S.; Mahapatra, S.C. Potential fly-ash utilization in agriculture: A global review. Prog. Nat. Sci. 2009, 19, 1173-1186. [CrossRef]

3. Hemalatha, T.; Ramaswamy, A. A review on fly ash characteristics-Towards promoting high volume utilization in developing sustainable concrete. J. Clean. Prod. 2017, 147, 546-559. [CrossRef]

4. Ahmaruzzaman, M. A review on the utilization of fly ash. Prog. Energy Combust. Sci. 2010, 36, 327-363. [CrossRef]

5. Yao, Z.T.; Ji, X.S.; Sarker, P.K.; Tang, J.H.; Ge, L.Q.; Xia, M.S.; Xi, Y.Q. A comprehensive review on the applications of coal fly ash. Earth Sci. Rev. 2015, 141, 105-121. [CrossRef]

6. Chaowasakoo, T.; Sombatsompop, N. Mechanical and morphological properties of fly ash/epoxycomposites using conventional thermal and microwave curing methods. Compos. Sci. Technol. 2007, 67, 2282-2291. [CrossRef]

7. Luo, Y.; Wu, Y.H.; Ma, S.H.; Zheng, S.L.; Chu, P.K. An eco-friendly and cleaner process for preparing architectural ceramics from coal fly ash: Pre-activation of coal fly ash by a mechanochemical method. $J$. Clean. Prod. 2019, 214, 419-428. [CrossRef]

8. Qian, B.; Hosseini, T.; Zhang, X.; Liu, Y.; Wang, H.; Zhang, L. Coal waste to two-dimensional materials: Fabrication of $\alpha-\mathrm{Fe}_{2} \mathrm{O}_{3}$ nanosheets and $\mathrm{MgO}$ nanosheets from brown coal fly ash. ACS Sustain. Chem. Eng. 2018, 6, 15982-15987. [CrossRef]

9. Xue, Y.; Yu, W.Z.; Jiang, W.Y.; Wen, L.; You, Z.X.; Lv, X.W. A novel process to extract alumina and prepare Fe-Si alloys from coal fly ash. Fuel Process. Technol. 2019, 185, 151-157. [CrossRef]

10. Querol, X.; Moreno, N.; Umaña, J.C.; Alastuey, A.; Hernández, E.; López-Soler, A.; Plana, F. Synthesis of zeolites from coal fly ash: An overview. Int. J. Coal. Geol. 2002, 50, 413-423. [CrossRef]

11. Querol, X.; Moreno, N.; Umaña, J.C.; Juan, R.; Hernández, S.; Fernandez-Pereira, C.; Ayora, C.; Janssen, M.H.M.; García-Martínez, J.; Linares-Solano, A.; et al. Application of zeolitic material synthesized from fly ash to the decontamination of waste water and flue gas. J. Chem. Technol. Biotechnol. 2002, 77, 292-298. [CrossRef]

12. Boycheva, S.; Zgureva, D.; Václavíková, M.; Kalvachev, Y.; Lazarova, H.; Popova, M. Studies on non-modified and copper-modified coal ash zeolites as heterogeneous catalysts for VOCs oxidation. J. Hazard. Mater. 2019, 361, 374-382. [CrossRef] [PubMed]

13. Zhang, X.; Gao, B.; Creamer, A.E.; Cao, Ch.; Li, Y. Adsorption of VOCs onto engineered carbon materials: A review. J. Hazard. Mater. 2017, 338, 102-123. [CrossRef] [PubMed] 
14. Liotta, L.F. Catalytic oxidation of volatile organic compounds on supported noble metals. Appl. Catal. B Environ. 2010, 100, 403-412. [CrossRef]

15. Białas, A.; Kuśtrowski, P.; Dudek, B.; Piwowarska, Z.; Wach, A.; Michalik, M.; Kozak, M. Copper-aluminum oxide catalysts for total oxidation of toluene synthesized by thermal decomposition of co-precipitated precursors. Thermochim. Acta 2010, 590, 191-197. [CrossRef]

16. Boycheva, S.; Zgureva, D. Surface studies of fly ash zeolites via adsorption/desorption isotherms. Bulg. Chem. Commun. 2016, 48, 101-107.

17. Zgureva, D.; Boycheva, S. Experimental and model investigations of $\mathrm{CO}_{2}$ adsorption onto fly ash zeolite surface in dynamic conditions. Sustain. Chem. Pharm. 2020, 15, 100222. [CrossRef]

18. Zgureva, D. Carbon dioxide adsorption studies on fly ash zeolites. Coal Combust. Gasif. Prod. 2016, 8, 54-59. [CrossRef]

19. Laugel, G.; Bingre, R.; Louis, B. Zeolite and silica-based $\mathrm{CO}_{2}$ adsorbents. In Post-Combustion Carbon Dioxide Capture Materials; Wang, Q., Ed.; The Royal Society of Chemistry: CPI Group Ltd., Croydon, UK, 2019; pp. 76-152.

20. Bonenfant, D.; Kharoune, M.; Niquette, P.; Mimeault, M.; Hausler, R. Advances in principal factors influencing carbon dioxide adsorption on zeolites. Sci. Technol. Adv. Mater. 2008, 9, 1-7. [CrossRef]

21. Walton, S.; Abney, M.; LeVan, M. $\mathrm{CO}_{2}$ adsorption in $\mathrm{Y}$ and $\mathrm{X}$ zeolites modified by alkali metal cation exchange. Micropor. Mesopor. Mater. 2006, 91, 78-84. [CrossRef]

22. Shigemoto, N.; Hayashi, H.; Miyaura, K. Selective formation of Na-X zeolite from coal fly ash by fusion with sodium hydroxide prior to hydrothermal reaction. J. Mater. Sci. 1993, 28, 4781-4786. [CrossRef]

23. Volli, V.; Purkait, M.K. Selective preparation of zeolite $X$ and A from fly ash and its use as catalyst for biodiesel production. J. Hazard. Mater. 2015, 297, 101-111. [CrossRef] [PubMed]

24. Franus, W. Characterization of X-type zeolite prepared from coal fly ash. Pol. J. Environ. Stud. 2012, 21, 337-343.

25. Zgureva, D.; Boycheva, S. Synthesis of highly porous micro- and nanocrystalline zeolites from aluminosilicate by-products. In Nanoscience Advances in CBRN Agents Detection, Information and Energy Security; Petkov, P., Tsiulyanu, D., Kulisch, W., Popov, C., Eds.; Springer: Dordrecht, The Netherlands, 2015; pp. 199-204.

26. Mendoza, E.Y.M.; Santos, A.S.; López, E.V.; Drozd, V.; Durygin, A.; Chen, J.; Saxena, S.K. Iron oxides as efficient sorbents for $\mathrm{CO}_{2}$ capture. J. Mater. Res. Technol. 2019, 8, 2944-2956. [CrossRef]

27. Li, Y.; Li, L.; Yu, J. Applications of zeolites in sustainable chemistry. Chem 2017, 3, 928-949. [CrossRef]

28. Huang, P.S.; Su, Ch.Y.; Lam, Ch.H.; Lee, W.Y.; Wang, Da.M.; Hua, Ch.Ch.; Kang, D.Y. Direct wet deposition of zeolite FAU thin films using stabilized colloidal suspensions. Micropor. Mesopor. Mater. 2018, 272, $286-295$. [CrossRef]

29. Lam, C.H.; Hsu, W.J.; Chi, H.Y.; Kang, Y.H.; Chen, J.J.; Kang, D.Y. High-throughput fabrication of zeolite thin films via ultrasonic nozzle spray deposition. Micropor. Mesopor. Mater. 2018, 267, 171-180. [CrossRef]

30. Wang, Z.; Yan, Y. Controlling crystal orientation in zeolite MFI thin films by direct in situ crystallization. Chem. Mater. 2001, 13, 1101-1107. [CrossRef]

31. Changjean, W.C.; Chiang, A.S.T.; Tsai, T.C. Anti-corrosion zeolite film by the dry-gel-conversion process. Thin Solid Films 2013, 529, 327-332. [CrossRef]

32. Caro, J.; Noack, M.; Kölsch, P.; Schäfer, R. Zeolite membranes-State of their development and perspective. Micropor. Mesopor. Mater. 2000, 38, 3-24. [CrossRef]

33. Hao, J.N.; Yan, B. Photofunctional host-guest hybrid materials and thin films of lanthanide complexes covalently linked to functionalized zeolite A. Dalton Trans. 2014, 43, 2810-2818. [CrossRef] [PubMed]

34. Angelomé, P.C.; Fuertes, M.C. Metal nanoparticle-mesoporous oxide nanocomposite thin films. In Handbook of Sol-Gel Science and Technology; Klein, L., Aparicio, M., Jitianu, A., Eds.; Springer: Cham, Switzerland, 2016; pp. 1-27.

35. Lazarova, K.; Boycheva, S.; Vasileva, M.; Zgureva, D.; Georgieva, B.; Babeva, T. Zeolites from fly ash embedded in a thin niobium oxide matrix for optical and sensing applications. J. Phys. Conf. Ser. 2019, 1186, 012024. [CrossRef]

36. Boycheva, S.; Zgureva, D.; Shoumkova, A. Recycling of lignite coal fly ash by its conversion into zeolite. Coal Combust. Gasif. Prod. 2015, 7, 1-8. 
37. Boycheva, S.; Marinov, I.; Miteva, S.; Zgureva, D. Conversion of coal fly ash into nanozeolite Na-X by applying ultrasound assisted hydrothermal and fusion-hydrothermal alkaline activation. Sustain. Chem. Pharm. 2020, 15, 100217. [CrossRef]

38. Murayama, N.; Yamamoto, H.; Shibata, J. Zeolite synthesis from coal fly ash by hydothermal reaction using various alkali sources. J. Chem. Technol. Biotechnol. 2020, 47, 280-286.

39. Boycheva, S.; Zgureva, D.; Vassilev, V. Kinetic and thermodynamic studies on the thermal behaviour of fly ash from lignite coals. Fuel 2013, 108, 639-646. [CrossRef]

40. Majchrzak-Kuceba, I. A simple thermogravimetric method for the evaluation of the degree of fly ash conversion into zeolite material. J. Porous Mater. 2013, 20, 407-415. [CrossRef]

41. Chanapattharapol, K.C.; Krachuamram, S.; Youngme, S. Study of $\mathrm{CO}_{2}$ adsorption on iron oxide doped MCM-41. Micropor. Mesopor. Mater. 2017, 245, 8-15. [CrossRef]

42. Lee, S.Y.; Park, S.J. A review on solid adsorbents for carbon dioxide capture. J. Ind. Eng. Chem. 2015, $23,1-11$. [CrossRef]

(C) 2020 by the authors. Licensee MDPI, Basel, Switzerland. This article is an open access article distributed under the terms and conditions of the Creative Commons Attribution (CC BY) license (http://creativecommons.org/licenses/by/4.0/). 